\title{
Renovación como responsabilidad ética en la perspectiva de la fenomenología*
}

Renewal as an ethical responsibility in the phenomenological perspective

Renovação como responsabilidade ética na perspectiva da fenomenologia

\section{Pedro Juan Aristizábal Hoyos** Oscar Eduardo Ocampo Ortiz ${ }^{* * *}$}

\footnotetext{
Artículo de investigación

Revista Colombiana de Educación, N.7 72. Primer semestre de 2017, Bogotá, Colombia

Para citar: Aristizábal, J., y Ocampo, O. E. (2017). Renovación como responsabilidad ética en la perspectiva de la fenomenología. Revista Colombiana de Educación, (72), 121-138.
}

Fecha de recepción: 01/08/2016

Fecha de aceptación: 07/12/2016

El artículo hace parte de la investigación sobre la respuesta ética a la crisis de las ciencias y las humanidades que se debate actualmente en las sesiones del grupo de investigación en fenomenología de la Licenciatura en Filosofía de la UTP

** Profesor titular de la Universidad tecnológica de Pereira. Director grupo de Investigación en: "Fenomeno logía y teoría crítica" juansipaso@utp.edu.co

*** Oscar Eduardo Ocampo. Profesor Universidad tecnológica de Pereira. Integrante del grupo de investigación en "Fenomenología y teoría crítica". oeocampo@utp.edu.co 


\section{Resumen}

El presente trabajo considera la ética como una actividad necesaria para la sociedad actual. La renovación ética del hombre y la cultura necesita la responsabilidad individual y colectiva de las personas. Esta consideración tiene su fundamento en el proyecto ético que Husserl promulgó en 1920. ¿Qué responsabilidad tiene el hombre frente a sí mismo y la cultura ante dicho proyecto histórico? Responder a esta pregunta implica indagar por la responsabilidad y la constitución del ser humano como persona crítica y libre. Partiendo de la experiencia del mundo de la vida como suelo fundamental, su propia racionalidad constituyente lo obliga a proponerse y construir horizontes de sentido. La presente reflexión se llevará a cabo en tres etapas. Primero se reflexiona acerca del método de la variación eidética y del fenómeno de lo dado en relación con el origen de la ética. En segundo lugar se propone la reflexión crítica como aspecto fundamental para la renovación del hombre y la cultura, y en la cual la autoconciencia, como conciencia de sí, es imprescindible en dicho proceso. En última instancia, y derivado de lo anterior, se presentan los conceptos de persona y de libertad como condicional de posibilidad de una sociedad ética, justa e incluyente.

\section{Palabras clave:}

Husserl, fenomenología, ética, reflexión crítica, persona, libertad.

\section{Keywords:}

Husserl, phenomenology ethics, critical reflection, person, freedom.

\begin{abstract}
This work aims to present ethics as a necessary activity in the current society The ethical renewal of man and culture requires the individual and collective responsibility of people. This consideration is grounded in one of Husserl's ethical projects from 1920. What is the responsibility of man to himself and to culture in such a historical project? To answer this question, one must investigate the responsibility and the constitution of the human being as a free and critical person. Taking the lifeworld experience as a fundamental ground, his own constituting rationality makes him engaged and elaborate horizons of sense. This reflection is developed in three stages. First, the article examines the method of eidetic variation and the phenomenon related to the origin of ethics. Second, it proposes critical reflection as a fundamental aspect for the renewal of man and culture, in which self-awareness as consciousness of the self is essential in such process. Last, and derived from the former, it presents the concepts of person and freedom as a condition of the possibility for an ethical, fair, and inclusive society.
\end{abstract}

\begin{abstract}
Resumo
O presente trabalho considera a ética como uma atividade necessária para a sociedade atual. A renovação do homem e a cultura precisa a responsabilidade individual e coletiva das pessoas. Essa consideração baseia-se no projeto ético que Husserl promulgou em 19200. Que responsabilidade tem o homem com sim mesmo e a cultura com relação a esse projeto histórico? Responder essa pergunta implica indagar pela responsabilidade e a constituição do ser humano como pessoa crítica e livre. A partir da experiência do mundo da vida como fundamento, sua própria racionalidade constituinte o obriga a propor e construir horizontes de sentido. A presente reflexão é feita em três etapas. Primeiro, uma reflexão acerca do método da variação eidética e do fenómeno do existente em relação com a origem da ética. Em segundo lugar, uma reflexão crítica como aspecto fundamental para a renovação do homem e a cultura, e na qual a autoconsciência como consciência de sim, é imprescindível nesse processo. Finalmente, e derivado do anterior, são apresentados os conceitos de pessoa e de liberdade como condição de possibilidade de uma sociedade ética, justa e inclusiva.
\end{abstract}

\section{Palavras chave:}

Husserl, fenomenologia, ética, reflexão crítica, pessoa, liberdade 


\section{Introducción}

Es conocida la preocupación de Husserl por la renovación ética del hombre. Ya en los ensayos de la revista The Kaizo (1922-24), decía: "La renovación del hombre, del hombre individual y de la colectividad humana, es el tema supremo de toda ética" (Husserl, 2002, p. 21). El concepto de responsabilidad ética se presenta en Husserl como fundamento de una renovación tanto humana como cultural. Dicha renovación no es posible sin la responsabilidad y la autorresponsabilidad del hombre individual y de la cultura humana en general. Esto se cimienta en una toma de conciencia de los actos libres y su configuración voluntaria por parte de la persona humana. La toma de conciencia y de valoración autónoma es, desde luego, efectuada sobre estructuras individuales y sociales prerreflexivas ya dadas, que implican, tomar posición a partir de actos valorativos y reflexivos.

Una perspectiva como la mencionada se relaciona con la vivencia personal del filósofo y su propio mundo cultural, marcado por la guerra, la fuerza y la imposición; estas, a diferencia del diálogo y la comunicación, producen una indescriptible miseria en todos los niveles de la sociedad humana. La guerra tiene un profundo impacto en la vida de Husserl, huella que deviene en la necesidad de una reflexión seria y responsable sobre la cultura europea. Tal idea está enmarcada dentro de la misma línea de las conferencias de 1917 sobre el ideal de la humanidad, de Fichte (Rizo-Patrón, 2013, p. 70).

La guerra que desde 1914 asola a Europa se caracteriza por sus diferentes medios de coacción: militar, política, económica, e, incluso, social y cultural, para así someter a los individuos a condiciones degradantes y frente a las cuales no somos ajenos. Este es un fenómeno vivido, y que más allá de conformarse con una descripción de cuanto sucedió, en el sentido de una realpolitik, exige una toma de posición valorativa y configuradora de nuevos actos fundantes, que permitan la renovación crítica y autónoma del estado de cosas. Desde ese punto de vista, si la guerra es un fenómeno, no es un fenómeno cualquiera para la conciencia, sino uno frente al cual hay que pararse con deseos de renovación para constituir una humanidad auténtica. Si el método fenomenológico es un análisis descriptivo de los actos y del fluir de la conciencia, no implica esto una descripción de la mera conciencia fáctica, sino que, más bien, se trata de encontrar las estructuras comunes, esenciales y necesarias subyacentes a estas desde la rigurosidad metódica. Por ello, afirmará Husserl: "La ética pura es la ciencia de la esencia y formas posibles de una vida de renovación tomada en generalidad pura (apriórica)" (Husserl, 2002, p. 21). 
Se propone, entonces, reflexionar sobre la ética y sobre la responsabilidad que de esta emerge, a partir de los ensayos de la revista The Kaizo y La Crisis, textos en los que Husserl presenta una posición ética y de construcción de sentido frente a la cultura europea, en la cual nuestras instituciones, nuestros sistemas de valores y nuestra propia configuración personal han sido establecidos.

\section{Lo dado, el método y el fenómeno ético}

¿Cómo se da el fenómeno ético? ¿Cuáles son su origen y su constitución? Lo primero que se puede resaltar es que, al igual que cualquier acto fundado en lo sensible, los valores también son dados. Hay, entonces, si se quiere, posibilidades objetivas de valorar lo moral. Pero la subjetividad constituyente propia de la reflexión trascendental no es lo más originario: previamente a ella, se tiene un mundo circundante, de formas de actuar, de valorar, y actos corporales que se nos dan de manera pasiva; es decir, sin concurso de lo más característico del ser humano racional y pensante: la reflexión. Si el postulado fundamental es ir a las cosas mismas, ¿cómo entenderlo? ¿Es ir a los hechos en bruto dados a la sensibilidad? Y si no es así, ¿qué papel juega la sensibilidad? ¿Es opuesta a las cosas mismas o a la reflexión constituyente? ¿O puede ser, incluso, complementaria a esta? Parece ser que no debe entenderse dicho postulado fundamental en el sentido de ir a los hechos empírico-psicológicos propios de una conciencia fáctica. La fenomenología debe, entonces, dar cuenta del fluir intencional de las vivencias, para constituir el sentido del ser de lo dado. Esto implica que los fenómenos, al poseer un carácter intencional, no se limitan a lo que se da a la intuición sensible, sino que abren un horizonte infinito de posibilidades temporales-espaciales, anímicas, valorativas, individuales y comunitarias de las vivencias. El objetivo es descubrir estructuras esenciales y necesarias que puedan determinar a priori la estructura de la conciencia. El darse de los fenómenos en Husserl no debe entenderse como el mero caso singular fáctico. El faktum es desbordado, ya que siempre es un punto de partida limitado. Sin embargo, su importancia radica, precisamente, en el hecho de ser punto de partida. La intuición dadora permite el proceso de la constitución reflexiva. Una donación que es, por esencia, una donación efectiva y afectiva en el mundo de la vida como suelo universal. Lo dado es, entonces, condicional de posibilidad de la reflexión posterior. Malet Patricio no duda en resaltar esta idea y relacionarla con la filosofía genética:

En este sentido, la intuición donadora, en el último periodo de la fenomenología Husserliana es completada con las investigaciones que Ileva Husserl sobre la génesis pasiva. En este paso de una fenomenología estática de las significaciones en Investigaciones Lógicas, a una 
fenomenología de la génesis de las significaciones lógicas (por ejemplo, en Erfahrung und Urteil), pasivas es que surge el tema del mundo de la vida o Lebenswelt. (Malet Patricio, 2009, p. 51).

En este sentido, dirá Husserl en Ideas I § 24, cuando menciona el principio de todos los principios. ${ }^{1}$ La intuición dadora de lo que aparece; debe aceptarse como eso que se da. Este es el punto de partida de toda reflexión como una modificación de la conciencia, y un abrirse de sus horizontes. Es así como la fenomenología no se queda con lo dado inmediatamente, sino que marca la necesidad y la responsabilidad de acceder a lo no dado, a partir de la reflexión de las vivencias, donde se amplía y se comprende lo vivido de manera significativa y llena de sentido.

Es así, también, como los objetos trascendentales no se dan de forma evidente e inmediata: la evidencia en relación con estos hay que ganarla, a partir de la abstracción ideatoria que surge del examen y el autoexamen de lo dado de manera inmediata y particular. El método de la intuición de esencias es lo que debe encontrar lo común a las percepciones y las vivencias de la propia conciencia, según enfatiza Dieter Lohmar al afirmar que dicho método consiste en encontrar "(...) aquello que permanece y que debe también permanecer idéntico en todos los posibles casos singulares de su objeto de descripción" (Lohmar. 2007 p. 11)². En este sentido es importante para Husserl señalar la manera en como debe recoger aquello que es a priori y esencial a las diferentes percepciones particulares. ¿Cómo recoge eso que es a priori —es decir, esencial—? No limitando el análisis y la descripción fenomenológica a los meros casos particulares dados de manera inmediata, sino, partiendo de ellos, hacer abstracciones para encontrar aquellas características comunes a los mismos. De acuerdo a lo anterior, plantea Lohmar que "La intuición de esencias, o sea, el método eidético, pretende no limitarse a hechos empíricos-contingentes, sino establecer relaciones aprióricas, o sea, necesarias que se apliquen a todo caso futuro y en general posible de un determinado fenómeno de la conciencia" (2007, p. 10).

Más aún, para esta tarea, la intuición categorial que propone Husserl presenta un aspecto determinante. La intuición categorial nos muestra que antes de cualquier reflexión u operación intelectual, las cosas nos son dadas de manera inmediata. De esta manera, Husserl, en Investigaciones Lógicas // § 47 afirma:

1 "[...] toda intuición dadora originariamente dadora es una fuente legítima de conocimiento; que todo lo que se nos ofrece en la "intuición" originariamente (por decirlo así, en su realidad en persona) hay que aceptarlo simplemente como lo que se da, pero también sólo en los límites en que ella se da" (2013, p. 51).

2 D. Lohmar. El método fenomenológico de la intuición de esencias y su concreción como variación eidética. Tomado de: Investigaciones Fenomenológicas 5: 9-47. 2007. SEFE. Sociedad Española de Fenomenología. Madrid UNED. 
En la percepción sensible se nos aparece la cosa "externa" de un solo golpe tanto como cae sobre ella nuestra mirada. Su modo de hacer aparecer como presente la cosa de modo simple, no necesita del aparato de los actos fundamentantes y fundados. (Husserl, 2014, p. 706).

Luego de mostrar el aparecer simple de la cosa a la intuición sensible, pasa Husserl a mostrar la distinción en el § 52 de esta misma investigación, la importante distinción entre la percepción inmediata de lo dado y la intuición categorial, donde ahora sí opera el aparataje entre actos fundantes y fundado en proceso de concatenación, a partir del que se puede acceder a una visión de conjunto por medio de unidades relacionantes y uniones ideales (Husserl, 1967). Los objetos de percepción pueden ser captados de forma inmediata y directamente, y de manera a-temática; es decir, son dados de un solo golpe. Ello implica que, en la percepción, antes de cualquier operación intelectual o reflexiva del yo, los objetos están ya ahí, dados de manera intuitiva. Ya en Ideas, el hecho de que el objeto se presente a la percepción no implica que se dé de manera reflexiva. Ponerlo a la reflexión implica sacarlo de ese darse pasivo y ponerlo ante la mirada. Por ello, dirá Husserl en Ideas / § 77: "Toda vivencia que no está ante la mirada puede convertirse, de acuerdo con una posibilidad ideal, en vivencia "mirada"; una reflexión del yo se dirige a ella, y ella se convierte entonces en objeto PARA el yo" (2013, p. 251). De manera similar, lo marcará después en Experiencia y Juicio $\S$ 17 , cuando menciona la orientación como eso que pone en vigilia al yo. "El estar despierto significa sufrir una afección eficaz; un trasfondo adquiere 'vida' objetos intencionales (...)" (Husserl, 1980, p. 85).

El acto de poner ante los ojos los objetos del mundo, en estricto sentido fenomenológico, supone también la donación del fenómeno tematizado; el esfuerzo de dicho acto está implicando la posibilidad de reflexión sobre aquellos que nos es dado, sobre sus modos de aparición, sus habitualidades y su generalidad en el más amplio sentido de la variación eidética. Variación eidética que muestra la pretensión de la filosofía de configurarse como una ciencia de fundamentación última y a priori, que introduzca una reflexión sobre la esencia racional del hombre espiritual y de sus formas de valorar, así como de la responsabilidad que emerge de allí. Y sin olvidar, además, que las ciencias del espíritu no son una mera existencia material y natural, sino que permiten emitir juicios racionales y normativos de acuerdo con normas generales que faciliten la dirección de la vida práctica. El método se convierte, según lo expone Husserl en las Lecciones de 1923-24, Filosofía Primera (1980), en un método de clarificación, en el cual lo a priori universal funciona como norma válida para todo caso particular pensado desde el ente en general (p. 15).

Lo dado no implica que todo se dé ahí, de manera inmediata, absoluta y definitiva: por el contrario, hay algo que no se muestra en lo dado, algo 
que no se hace efectivo, pero se puede hacer claro y evidente, mediante el recorrido de las percepciones que hace la intuición categorial partiendo de esto dado. Así lo expresa Lohmar: "La intención categorial y también la intuición categorial exigen por el contrario una sucesión de actos formada por actos articulados y fundantes, posteriormente son coaprehendidos mediante un acto englobante dotado de una intención nueva, de un nivel superior" $(2005$, p. 13). Este es un principio fundamental de la fenomenología, pues volver a las cosas mismas solo es posible sobre la base de actos fundantes y fundados en el fluir intencional de la conciencia. La intuición de esencias es descrita por Husserl en el $\S 52$ de la sexta investigación lógica como una forma particular de la intuición categorial; se presenta una división triple: percepción particular, percepción global y síntesis categorial. Para el caso de la intuición de esencias, esta misma división triple se nos presenta como: percepción, creación de variantes y síntesis de cumplimiento. Lo que se puede ver es que tanto la intuición categorial como la intuición de esencias parten de la percepción; es decir, lo dado de inmediato a la intuición sensible. Y es, precisamente, esto lo que resalta Lohmar en su texto. El objetivo es encontrar el a priori, lo esencial y común a las múltiples percepciones particulares. Ni la seguridad ni la evidencia de dicho procedimiento metódico se encuentran a su inicio, sino al final.

\begin{abstract}
Cuando reformulamos [Umfiengieren] en múltiples y limitadas variaciones posibles a través de la percepción de la fantasía del objeto contemplado según libre modificación y advertimos el mismo elemento en todas ellas, entonces podemos estar seguros que en los casos siguientes también estará presente, es decir, se trata de algo necesario y apriórico en el sentido de la intuición de esencias. (2005, p. 17).
\end{abstract}

Es la rigurosidad del método de la variación de esencias lo que nos permite traer a la luz lo que no está presente de manera inmediata, pero ya está implícito en ello. Tanto la intuición categorial como la propia intuición de esencias se dan dentro del marco de la dilucidación del conocimiento, que tiene el carácter de necesidad y de generalidad metódica (Lohmar, 2004). Pero, ¿qué relación tiene eso con la ética? La respuesta la da el propio Husserl cuando habla de la Renovación y el problema del método, en el sentido de que el hombre no debe conformarse con afirmar el método a priori, riguroso y sistemático tan solo en las ciencias de la naturaleza. Por el contrario, la renovación implica una renovación del método en relación con las ciencias del espíritu; especialmente, en la ética, como ciencia fundante, en la cual también debe acaecer el modo de abstracción para llegar al a priori.

Desde las lecciones de 1920/24 se presenta un cambio a partir de las lecturas de Fichte; sobre todo, su concepto de persona, concepción marcada por una idea de oposición al naturalismo, lo que le obliga a tratar 
los juicios éticos desde un punto de vista normativo, y al hombre, como a un ser no solo teórico, sino volitivo y práctico. El hombre, no es simplemente un ser mecánico, en el sentido del mecanicismo planteado por el médico y filósofo J. O. La Mettrie, en su obra L'homme Machine (1748); el hombre no está supeditado al instinto, los impulsos y las tendencias, sino que puede poner restricciones a estas, tranzarse por nuevas tomas de postura y de construcción de nuevos fines y horizontes de sentido.

El hombre, tanto como el animal, es un ser sentiente -incluso, tendencioso-, que reacciona a los impulsos y las afecciones de sus percepciones, pues compartimos un mundo circundante, común a todos, un mundo de la vida, como suelo universal. Por eso, se opondrá tanto Husserl, en Crisis, a que el hombre sea visto sólo como un "(...) ser corporal ser extensional-coexistente bajo ciertas circunstancias (...) El naturalismo considera a los hombres como extensión llena y, de este modo, considera el mundo en general tan solo como una naturaleza ampliada" (1991, pp. 302-303). Lo que se ve aquí es una crítica al hecho de percibir el mundo en general - $y$ al hombre, en particular - como mera extensión, determinable por la cuantificación sin más. Hay una oposición crítica a este postulado, pues Husserl propone una idea del hombre como ser espiritual encarnado. En Crisis dice al respecto: "(...) toda vida anímica humana está fundada sobre lo corporal, por lo tanto, también lo está toda comunidad en los cuerpos de los miembros individuales que son sus miembros" (1991, p. 325). Por ello, para poder entender su constitución espiritual, el ser humano debe retroceder a la comprensión de su propia corporeidad. Pero el hombre, a diferencia del animal, no se define solo por su cuerpo, el de sus percepciones, sus sensaciones y sus tendencias, ya que este no solo es afectado, sino auto-afectado, tiene una capacidad o una facultad cognoscitiva y reflexiva para tomar distancia de estos y dirigirse a construir fines más elevados y más positivos, o bien, para reiterarlos si no los considera y los valora positivamente.

La investigación pura de esencias y la correspondiente abstracción de esencias, en el sentido de abstracción de conceptos puros y aprióricos dados en la matemática, no deben ser solo un privilegio de esta. El hombre, el ser humano, está Ilamado, por su propia racionalidad inherente, a dar cuenta de forma detallada de sus actos, de sus formas de valoración, y a guiar estos por una vida de razón. Por ello nos dirá Husserl:

Por poco habitual que nos resulte practicar tal modo de abstracción en la esfera del espíritu e indagar en ella su a priori: las necesidades de esencia del espíritu y de la razón, sin duda es igual de posible aquí que allí. (2002, p. 10).

De esta manera, si no hay un comienzo rigurosamente científico, no hay una ciencia en sentido estricto. Esta concepción implica una ciencia 
regida por reglas de la razón, reglas que diseñan previamente y configurarán el camino por seguir, con rigor metódico, dentro de la investigación; pero, a diferencia del naturalismo, aquí el método no se toma de forma determinística, para cuantificar el mundo y al hombre, sino para construir, a partir de patrones comunes, con cierta universalidad, una ciencia ideal y en constante desarrollo. No implica lo anterior que se estén descartando reglas y normas particulares: por el contrario - dice Husserl-, estas son configuradas de forma sistemática; es decir, teleológicamente. Dicha ciencia no está absolutamente definida, sino que se desarrolla de manera progresiva, es incesante e ideal. Por ello, dirá Husserl en Filosofía Primera: "Y en el punto más alto tiene la ciencia una teoría unificante ideal, una teoría universal que se amplia y eleva indefinidamente de acuerdo con el avance incesante de la ciencia" (1998, pp. 1015). Dicha idea de ciencia implica una concepción amplia de la razón, donde lo teórico, lo volitivo y lo valorativo se presentan diferenciados en una idea unificada de la razón.

\section{La renovación como reflexión crítica constituyente de nuevo sentido}

A Husserl se le ha criticado por querer hacer de la filosofía una ciencia rigurosa, basada en la intuición dadora. Ir de los objetos dados a los actos de la conciencia (vivencias intencionales) para encontrar en ellos estructuras generales e ideales; esto se concibe como una pretensión ingenua, que lleva el conocimiento a una elevada especulación vacía e idealizadora. No obstante, lo que Husserl manifiesta es el poder de la razón para encontrar la evidencia de la totalidad del ser como algo dado. El hecho de que la razón pueda acceder a la estructura de la conciencia y examinar el origen de sus vivencias y sus patrones comunes implica que la reflexión es un fenómeno posterior a la vivencia, posibilita también emitir juicios de experiencia como juicios de razón que en términos de Husserl son en general vivencias psíquicas, o actos intencionales, así que toda reflexión se halla cimentada en estructuras dadas, pre-reflexivas. Se puede pensar que muchas de nuestras acciones cotidianas, como comer, saludar, caminar, sentirse atraído por un objeto u otro, se dan sin necesidad de reflexión. Es sobre esto, precisamente, sobre lo que aplican la reflexión y la vida consciente del yo trascendental. También se puede decir que todo juicio cognitivo o ético se basa en estructuras dadas y establecidas sin más: por ejemplo, costumbres u opiniones, o, incluso, tipos diferentes de formación social, cultural o religiosa. La reflexión debe poner en claridad esas consideraciones tanto en lo cognitivo como en lo ético.

Cuando el propio Husserl remarca la importancia de Sócrates frente a la lucha clarificadora que debe hacer la razón para salvar no solo la

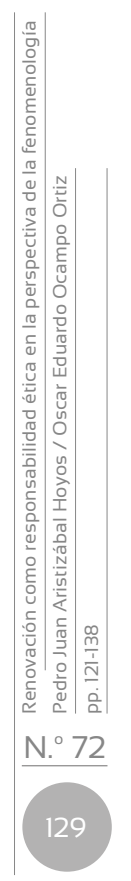


ciencia, sino también las convicciones éticas frente al escepticismo de los sofistas, no deja de recalcar que partimos de un mundo circundante dado sin más. Toda actividad —dirá Husserl en Filosofía Primera- está “(...) motivada por opiniones sobre la existencia de las realidades del mundo circundantes y opiniones de valor: sobre lo que es bello y feo, bueno y malo, útil e inútil, etc." (1998, p. 22). Dichas opiniones son vagas generalmente, pero no necesariamente; lo determinante en dicho análisis es el rescate de la doxa y de una doxa primordial sobre la que se levanten la reflexión y todo conocimiento posterior. De esa manera, los elementos de la constitución del sentido deben asumir estas opiniones. Así lo dice Rizo-Patrón:

Por ende, la filosofía primera amplía su espectro y halla sus límites cuando el método fenomenológico pasa de un procedimiento 'estático', cuyos hilos conductores son la eidética y la evidencia, a uno 'genético' y teleológico. Los datos estructurales y evidencias eidéticas puestas al descubierto con la 'fenomenología estática', se abordan en la 'fenomenología genética' desde el punto de vista de su 'historia temporal'. (2013, p. 344).

Ahora bien, el hecho de que Husserl mantenga en toda su obra una prioridad reflexiva del yo, no implica que desprecie otros niveles de desarrollo. Al contrario de lo que se opina a menudo, Husserl sostiene un nivel objetivante, uno valorativo y uno práctico, que se complementan a partir de niveles cada vez más amplios de desarrollo. Pero para comprender esto, es necesario comprender la razón en un sentido amplio de unidad y análisis diferenciado. Dicha idea aparece como tema principal de la Filosofía primera:

En concordancia, la idea apodíctica de la filosofía, abarca toda suerte de producciones subjetivas autorresponsables que se esfuerzan por alcanzar la verdad absoluta. Esto explica la interrelación de la lógica formal, la axiología y la teoría práctica con sus respectivas verdades teóricas, valorativas y prácticas. (1998, p. 337).

Así, la reflexión, como tema capital de Ideas I, y a la que se ha criticado como un mero ejercicio especulativo e ideal, no hace plena justicia al pensamiento de Husserl, pues solo es una mirada parcializada. Sin duda, para comprender esta idea hay que hacer una visualización del pensamiento de Husserl desde su totalidad y sus constantes desarrollos. Para ello, se puede partir de etapas pre-reflexivas, instintivas, kinestésicas. Tal idea es considerada repetidamente por Iribarne y San Martín, en consonancia con Husserliana $X V^{\beta}$.

3 En textos como De la ética a la metafísica y la réplica al texto El problema de la experiencia del otro y el sentido de una ética fenomenológica, el V Coloquio Latinoamericano de 
Por lo planteado, ver a Husserl únicamente desde una concepción estática implica no solo no comprender sus postulados, sino desfigurar su pensamiento. La fenomenología implica una dinámica reflexiva que se da desde ciertas actividades dóxicas, pasivas; si se quiere, en la esfera de la pre-reflexividad. Es de esta manera como se abre el horizonte para entender las vivencias, las diferentes formas de valorar y la misma responsabilidad ética. El indagar y el reflexionar retrospectivo de la fenomenología estática descubren la subjetividad trascendental, pero esto no es lo único. Hay, si se quiere, un ámbito o nivel previo: lo asociativo y pasivo, que el yo trascendental, consciente, debe presuponer como previo a su actividad. De esta manera, entra en juego un nivel teleológico, que permite comprender lo corporal, lo irracional-sensitivo y ciertos sentimientos morales determinantes para la ética. Ello, a su vez, permite a la fenomenología servir de fundamento, según Guillermo Hoyos (2002), a sólidas propuestas contemporáneas de argumentación moral y ética, como las de Habermas y Tugendhat ${ }^{4}$. De igual manera, dentro del campo de la formación y la educación se han presentado fuertes argumentos sobre la importancia de educar en valores morales, y se acude para ello a la ética fenomenológica, a su relación con sentimientos morales y a su importancia para tal fin.

Lo anterior, no es opuesto a lo reflexivo; por el contrario, permite “(...) reconstruir y describir este desarrollo teleológico previo desde la vida pasiva, pre-egológica, pre-objetivante asociativa hacia la vida racional activa, consciente, y finalmente plenamente desarrollada" (Rizo-Patrón, 2013, p. 343). En ese orden de ideas, el fluir de las vivencias y la constitución de sentido establecen identidad personal, social y colectiva. Pero dicha constitución no se hace en soledad reflexiva: previamente a ello, vivimos de manera pasiva, impulsiva, irreflexiva; nuestro ser se empieza a conformar siempre en relación con otros: el otro está ahí, hace parte de mí, de mi proyecto, de mi historia. En Crisis, Husserl remarca esa idea de la relación con los otros al decir: "El yo que experimenta, que vive (valorando, actuando, corrigiendo sus tendencias), ese Yo tiene un Tú, un Nosotros y un Vosotros (1991, p. 278). Aquí se puede ver y entender el desarrollo de los sujetos a partir de diferentes eslabones, movido, desde luego, por percepciones, intereses, motivaciones, posibilidades y valoraciones de carácter práctico hacia una vida plena de conciencia y actos libres bajo los primados de una vida plenamente racional.

Fenomenología. $150^{\circ}$ Aniversario del nacimiento de Husserl \& 10 (Iribarne, 1995 \& 2009). De igual manera, Javier San Martín propone ver a Husserl no fragmentado por una lectura de sus primeras obras, sino a partir de la completud de su obra; especialmente, los textos que tienen que ver con la generatividad y con la filosofía genética. Así lo expresa también San Martín en su texto La nueva imagen de Husserl. Lecciones de Guanajuato (2015).

4 Hoyos, G. (2002), Introducción a Renovación del hombre y la cultura. Cinco ensayos. (pp. VII-XXXIII)

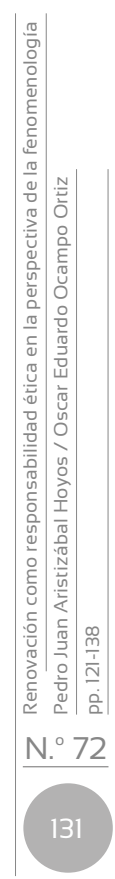


En tal sentido, el mundo dado ahí, en actitud natural, de manera pre-reflexiva, no nos exime de la responsabilidad de pensarlo. Pero antes de pensar y reflexionar sobre él o en la multiplicidad de vivencias y objetos, estos se nos dan de manera ingenua y pasiva; dicha idea es resaltada en el texto El solipsismo y las relaciones de intersubjetividad: "Este mundo pre-dado, se presenta a una intuición primariamente sensible. En el mundo ahí captado, encontramos, cosas, animales y hombres; un mundo de seres envueltos en el espacio tiempo del mundo vital" (Aristizábal, 2014, p. 80).

Si el yo vive - por lo general, ingenuamente- en este mundo, en el más puro e ingenuo realismo, hay una necesidad de renovación de esa ingenuidad, de hacer epojé para suspender dicha actitud natural. Eso, debido a que el yo, por carácter real y posible de verse a sí mismo en sus experiencias vitales, puede mantener estas o cambiarlas para proyectase de otro modo en la historia individual, familiar o social.

La realidad espiritual del hombre, del yo-sujeto, no carece de racionalidad. Si bien esta tiene su propia intimidad - o sea, se diferencia de lo meramente natural dado en mera objetualidad-, se constituye sobre sobre un yo-centro individual que tiene sus propias motivaciones. Dichas realidades individuales "sujeto-yo" no se quedan en su individualidad, sino que entran en compresión de relación mutua con otros yo-sujetos por medio de actos sociales de conciencia, según lo manifiesta Husserl en The Kaizo: “(...) la forma de la colectividad que se unifica espiritualmente, por medio de momentos íntimos, por medio de actos y motivaciones intersubjetivas" (2002, pp. 6-7). Aquí ya no se elaboran juicios únicamente teóricos, relacionados con meras cuestiones de hecho, sino que entran a actuar motivaciones, tendencias, sentimientos, formas de valorar, de querer y de pensar. El ser humano puede hacer todo eso, por cuanto es un ser espiritual, ser-sujeto de cualidades intelectuales y morales, que lo obligan a no quedarse con su pasado recordado, o con su presente vivido, sino a desplegar un futuro expectante, idealizado y esperanzador.

Se puede, entonces, entender la responsabilidad irrenunciable y radical del hombre de pensar su mundo, de reflexionar sus instituciones, sus acciones, de poner a estas entre paréntesis cuando aprecie, crea y piense que no son las apropiadas; también puede, partiendo de ello, redirigir su sentido de vida. La renovación se considera así un imperativo, como un "clamor presente", frente a un mundo basado en meros hechos, donde no hay cabida para pensar los problemas esenciales de la vida y la existencia humanas, sobre Dios, sobre la existencia del mundo, del hombre y de la libertad, según se pronuncia Husserl en los §§, 2, 4 y 5 de Crisis; todo eso, debido a que no son hechos fácticos (Husserl, 1991). Es claro que para dicha renovación se necesita una responsabilidad, un sentirse no conforme, tener la determinación de promulgar la inconfor- 
midad con argumentos sólidos, pero siempre responsables, frente a la individualidad y la libertad del otro, que también piensa y siente su mundo.

¿Qué responsabilidad tiene el hombre teórico, humanista, frente a la sociedad y la cultura? Para Husserl, todo conocer científico conlleva un primado de coherencia; el saber implica un hacer, una actividad cognitiva y ética, si dicha actividad es seria y auténtica. De ahí la radicalidad y la responsabilidad científica, pero, más allá de eso, según expresa Husserl en Renovación del hombre y la cultura, debajo de todo análisis, cuestionamiento y crítica, se esconde el anhelo humano de ser mejor. "Si pronunciamos un juicio reprobatorio sobre nuestra cultura, o sea, sobre la cultura con que nuestra humanidad se cultiva a sí misma y cultiva el mundo que la rodea, ello implica que creemos en una buena humanidad como posibilidad ideal" (2002, p. 8). Cuando Husserl menciona la necesidad de fundar una ciencia rigurosa, última y auténtica, que presupone para su fenomenología trascendental, no está marcando una ciencia acabada y absoluta. Por el contrario, nos está presentando un orden de prioridades organizadas y configuradas de manera sistemática, teleológica, de acuerdo con un avance incesante y absoluto de la ciencia (Husserl, 1998).

Dicha ciencia, que se amplía gradualmente por la razón y la reflexión, no surge espontáneamente, sino de un constante desarrollo histórico, del análisis y la crítica de problemas, que no se conforma con validar tal o cual pensamiento filosófico, sino de clarificar, de traer a la luz, lo que nos ha llegado y se nos ha dado como con-figurado. Por ello, no duda Husserl en decir que la filosofía primera se debe establecer como una "(...) filosofía de los comienzos que se confirma a sí misma en la más radical autoconciencia filosófica y en la más absoluta necesidad metódica" (1998, pp. 17-18).

Pero si dicha filosofía está destinada a renovar el ambiente espiritual y cultural, como presupone Husserl, eso implica que lo dado debe ser analizado para poder emitir un juicio sobre ello. Por tal razón, debemos regresar a nuestro ser más primigenio, a lo corporal, lo instintivo, lo estimativo, y así poder comprender nuestra naturaleza. A la vida de la conciencia, entonces, no podemos acceder solo por vía causal, sino encontrando lo íntimo de la vida espiritual; es decir, el mundo interior, lleno de impulsos, sentimientos, creencias y razones. Se puede ver aquí, por un lado, la relación que existe entre los textos The Kaizo y Crisis; por otro, se muestra una oposición crítica importante a no dejarse determinar por meras cuestiones de hecho. En el reino del espíritu humano, y a diferencia de la naturaleza, no solo hay juicios teóricos que incumben a "cuestiones de hechos", sino que surge "(...) una forma enteramente nueva de enjuiciamiento y racionalización de todo lo espiritual, a saber: lo que procede según normas, según disciplinas apriórico-normativas de la razón, de la razón lógica, de la razón estimativa y de la razón práctica" 
(Husserl, 2002, pp. 8-9). No está de más decir que dicha fuerza debe emerger de la responsabilidad, la seriedad y la conciencia en nuestra propia racionalidad, y, en especial, del filósofo llamado por su espíritu a combatir desde su actividad crítica toda imposición injusta, degradante y violenta que atente contra la persona y la humanidad, posición que hunde sus raíces en el escepticismo y el dogmatismo. Son estos dos los elementos que más alertan a Husserl. La filosofía no es verdadera filosofía, sino que es diálogo con el otro; la ética no se constituye sobre la individualidad y el egoísmo, el cual no solo es teórico, sino que alcanza a nuestras familias, a nuestros amigos, a nuestros maestros y a nuestras instituciones. Pero esto no debe hacernos caer en el escepticismo, sino motivar nuestra voluntad para encontrar claridad y conocimiento de la realidad, no solo y únicamente de forma individual, sino, esencialmente, como colectividad humana.

\section{El hombre como ser personal libre}

Husserl plantea en Crisis (1991) la ratio como un constante movimiento de auto aclaración (p. 281) Esta afirmación nos ubica, de entrada, en una idea de la razón, no estática, sino dinámica; es decir, un continuum de desarrollo histórico y teleológico. Dicha razón y dicha reflexión conscientes parten de un mundo universalmente compartido, donde se dan subjetividades relativas. Es el mundo pre-dado, el cual compartimos hasta con la ciencia objetiva y naturalista, es el mundo sobre el cual se configuran, incluso, las relaciones de intersubjetividad. Este mundo dado, después de la reducción trascendental, ya no será un simple mundo natural, sino un mundo espiritual e histórico, sobre el que Husserl intenta construir una ciencia universal y teleológica, sobre la cual se constituye no solo la persona humana, sino, también, el más elevado ideal de humanidad: la autonomía. "(...) la ciencia universal fundamentada y fundamentante de modo apodíctico se origina como la función necesariamente más elevada de la humanidad, a saber: la función, como decía, de hacer posible su desarrollo hacia una autonomía personal y hacia una autonomía humanitaria (...)" (Husserl, 1991, pp. 280-281).

En esta idea, lo que se pone en juego es el objetivo esencial para una auténtica humanidad: la autonomía. Pero antes de comprender esto, es necesario partir de un mundo dado, donde se nos dan la totalidad de los entes a la tematización. Aquí la intencionalidad de la conciencia juega un papel esencial, por el hecho de que siempre hace referencia a objetos dados en el mundo, pero también orienta al yo a horizontes abiertos de sentido. La dirección temática que se abre frente a la mirada permite descubrir que en este horizonte del mundo hay otros. Eso es lo que Julia Iribarne resalta como el carácter intersubjetivo de la subjetividad, donde 
la relatividad de subjetividades descubre un horizonte abierto de posibilidades y expectativas individuales y colectivas. El mundo es:

El vínculo trascendental del "uno en el otro" y del "uno con el otro" (incluidas las modalidades del "uno según el otro", "uno para el otro", "uno junto al otro)" que se encuentra en una u otra modalidad de todos los estratos a que se aplique la mirada del fenomenólogo. El estrato social exhibe un estrato alto de constitución. (Iribarne, 2007, pp. 131-132).

Nos encontramos con otros; por la mirada, por gestos y por palabras, se comparten ideales y creencias. Nos constituimos a partir de comunidades naturales como la familia, o por la idea de querer constituir una comunidad voluntaria, como grupo de amigos, de estudio, etc. "(...) los hombres viven siempre, por razones obviamente generativas, en comunidades, familia tribu, nación, y éstas se articulan, a su vez, en sí mismas, de modo más o menos rico, más o menos pobre, en socialidades especiales" (Husserl, 1991, p. 336). Pero la comunicación se hace, incluso, sobre los que están ausentes, a partir del recuerdo, o de asumir tareas que otros dejaron. Es claro que aquí accedemos a una vida espiritual que ya no está marcada por lo externo, sino por motivaciones internas que constituyen comunidades. Aquí se presenta la comunicación como lo que no nos permite caer ni permanecer en la soledad, sino que entabla lazos de unidad, esenciales para la vida práctica, asumiendo el pasado, venciendo el presente y proyectando ideales futuros.

Este proceso, que se constituye desde las esferas más primordiales hasta las más elevadas, tiene en la capacidad volitiva de decisión humana su elemento más definitorio. Por ello, es claro que el hombre siempre se propone ciertos fines, y debido a esto es un ser histórico, consciente de sí y de los otros que están a su alrededor; característica propia de él, que, a diferencia de los animales, siempre se configura de modos diversos, distintos. "El simple animal actuará acaso del mismo modo una y otra vez, dadas determinadas circunstancias, por ejemplo, pero carece de voluntad en la forma de generalidad" (Husserl, 2002, p. 26). Esta es, sin duda, una de las razones por las que Iribarne, siguiendo a Husserl, resalta constantemente que la vida humana es un constante aspirar, y un aspirar positivo que se concreta, precisamente, en la vida práctica de los hombres y las mujeres. "El aspirar a la satisfacción se funda en la estructura trascendental de la vida práctica, que es esencialmente capaz de precaptar sus objetos (en sentido lato) y preverse y preverlos en el futuro" (Iribarne, 2007, p. 137).

Si la razón es lo más esencial y especifico en el hombre, en cuanto ser que vive su actividad en habitualidades de carácter personal, es, precisamente, porque puede aspirar y proponerse cosas. Por ello, dice Husserl, en Crisis: "La vida humana personal discurre en niveles de auto-

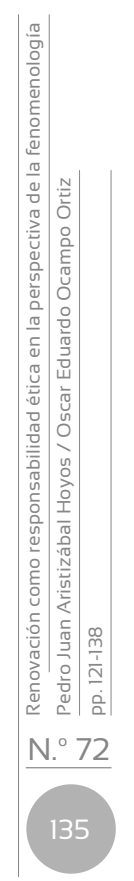


rreflexión y autorresponsabilidad desde los actos aislados y ocasionales de esta forma hasta el nivel de la autorreflexión y autorresponsabilidad universales, y hasta la aprehensión conciencia de autonomía (...)" (1991, p. 280). La idea de persona no es, entonces, un ser constituido aisladamente, sino uno constituido en relación con otros; incluso, "una racionalidad unilateral puede convertirse así en un mal” (p. 348). Y no por ello deberá el ser humano olvidar su más importante constitución definitoria, esa que lo hace no solo persona, sino auténticamente libre.

Solo el genuino examen personal (inspesctio sui), de donde deriva su toma de postura reflexiva de su propia vida y del mundo que lo rodea, constituye la vida humana autentica. Por ello, dirá Husserl:

El hombre tiene la peculiaridad esencial de "actuar" libre y activamente desde sí mismo, desde su yo-centro, en lugar de estar entregado pasivamente y sin libertad a sus impulsos (tendencias, afectos) y de ser en el sentido más amplio, movido efectivamente por estos. (Husserl, 2002, pp. 24-25).

Esta radical idea de libertad mueve al hombre a asumir una vida de valores positivos frente a sí, frente a su cultura; una exigencia de vida perfecta que lo constituye como a una personal racional y libre.

Aspirar a una vida racionalmente auténtica, que nos permite salir de la duda y suspender tanto tendencias como afectos, si estos nos pueden llevar a la aniquilación, es la vida de una persona que ejercita del mejor modo la posibilidad de su razón y su razonabilidad práctica. Dicha idea, de una vida autentica, racional y consciente, debe ser un primado, un clamor de la formación y la educación humanas. Las humanidades hoy día pierden su rumbo, y con ellas, la educación y la construcción auténtica del sentido y del deber-ser de la sociedad y las intuiciones. Si la ciencia y las humanidades pierden su horizonte social y ético, es porque han perdido su racionalidad, y, con ello, toda su actividad social trasformadora. A esto se refiere Husserl en relación con los griegos, bajo el escepticismo de los sofistas frente a la ética: "Toda actividad quedaba deshojada de sus fines normativos estables y pérdida de vigencia la idea de una vida práctica regida por la razón" (1998, p. 21). Dicha advertencia, surgida del análisis serio que Husserl hace del pasado, podría igualmente sucedernos hoy, sociedad movida por la ingenuidad de la apariencia, de las ciencias particulares y su exacerbada especialización. Solo a partir de la ardua y penosa tarea de la razón es como podemos valorar las actividades prácticas de la vida. La vida auténtica es la que constituye el hombre que vive en la razón, por cuanto es así como emerge: "La conciencia de la responsabilidad de la razón o conciencia moral (...)" (Husserl, 2002 p .34), que puede emitir juicios frente a situaciones particulares, y corregirlas si es necesario, y donde partiendo, incluso, de 
motivos originarios, se pone en juego la consideración libre, consciente y responsable del hombre.

Esta capacidad de optar por cuestiones elevadas y absolutas es lo que mueve al hombre a una renovación de sí mismo y de la cultura. Una ética no anclada en instintos ni en pasiones, sino en la razón, y que permite la autorregulación y la constitución de la vida. Constitución bajo los más nobles ideales de vida ética y de justicia social. Pero si el hombre puede hacer eso es porque puede ser consciente y autoconsciente de sus acciones, de sus responsabilidades. Solo el hombre que puede formarse a sí mismo bajo los nobles ideales de la justicia y una ética social auténtica es un ser persona auténticamente libre. Pero esto no sucederá si el ser humano no hace efectiva su reflexión racionalidad crítica.

Por lo expuesto, Husserl no duda en afirmar al final de Crisis: "solo cuando el espíritu retorne a sí mismo desde su orientación ingenua hacia lo exterior y permanezca en sí mismo y puramente en sí mismo, podrá dar razón de sí mismo" (1991, p. 356)". Es claro que dicho ideal está fundado en la idea de que el hombre se conozca a sí mismo, como ser racional, pensante y consiente de sus propias actividades de comprensión. Ello concuerda, de manera adecuada, con lo propuesto en Filosofía primera, cuando dice el autor que una verdadera y auténtica vida racional, especialmente, "(...) debe superar completamente el nivel de la ingenuidad por medio de la reflexión radical clarificadora, en el caso ideal debe poder justificar perfectamente cada paso, pero, ante todo, la justificación tiene que prevenir de principios racionales" (Husserl, 1998, p. 26). La renovación que propone Husserl surge de la motivación de que el mismo hombre y la sociedad sean mejores, una vida de trasformación que el ser humano debe proponerse como fin histórico y social. "Esta es una vida de la que el ser humano, en incansable autorreflexión y radical examen de sí mismo, crítica -evaluando definitivamente- sus propósitos vitales y, claro está, los medios para alcanzarlos, las vías para llegar a ellos" (1998, p. 21).

\section{Referencias}

Aristizábal, P. (2014). El Solipsismo y las relaciones de intersubjetividad. Análisis fenomenológico de la experiencia del otro. Bogotá: San Pablo.

Hoyos, G. (2002). Introducción. La ética fenomenológica como responsabilidad para la renovación cultural. En: E. Husserl. Renovación del hombre y la cultura, pp. VII-XXXIII. Barcelona: Anthropos.

Hoyos, G. (2007). Ética fenomenológica y sentimientos morales. Anuario Colombiano de Fenomenología, volumen I, 19-25. Universidad Tecnológica de Pereira. 
Husserl, E. (1980). Experiencia y Juicio. Investigación acerca de la genealogía de la lógica. (Redacción y edición de Ludwing Landgrebe; traducción de Lothar Eley \& Jas Reuter). México: Universidad Nacional Autónoma de México.

Husserl, E. (1991). La crisis de las ciencias europeas y la fenomenología trascendental. Una introducción a la filosofía fenomenológica. (Trad. castellana y notas editoriales de Jacobo Muñoz \& Salvador Más). Barcelona: Crítica.

Husserl, E. (1998). Filosofía Primera (1923/24). (Trad., Rosa Elena Santos de Ilhau). Santafé de Bogotá: Editorial Norma.

Husserl, E. (2002). Renovación del hombre y la cultura. Cinco ensayos. Agustín Serrano de Haro (Trad.); introducción, Guillermo Hoyos Vásquez. Barcelona: Anthropos.

Husserl, E. (2013). Ideas relativas a una fenomenología pura y una filosofía fenomenológica. A. Zirión. México: FCE.

Husserl, E. (2014). Investigaciones Lógicas II. Madrid, Alianza Editorial S. A.

Iribarne, J. (2007). De la ética a la metafísica. En la perspectiva del pensamiento de Husserl. Bogotá: San Pablo.

Iribarne, J. (2012). Réplica al texto "El problema de la experiencia del otro y el sentido de una ética fenomenológica de P. Enrique García $R^{\prime \prime}$. Acta fenomenológica latinoamericana. Volumen IV. Pontificia Universidad Católica del Perú (pp. 223-230).

Lohmar, D. (2004) El concepto de la intuición categorial en Husserl. (Trad. Prof. Kurt Späng; revisión técnica: Alejandro G, Vigo). Anuario Filosófico, XXXVII/1 (pp. 33-64).

Lohmar, D. (2007). El método fenomenológico de la intuición de esencias y su concreción como variación eidética. En: revista Investigaciones fenomenológicas. 5: 9-47. SEFE. Sociedad Española de Fenomenología. (UNED) Madrid.

Mena, P. (2009). El mundo de la vida y lo cotidiano. Actual Marx/Intervenciones (8).

Rizo-Patrón de Lerner, R. (2013). La responsabilidad como fundamento último de la filosofía. En: Investigaciones fenomenológicas, Vol. Monográfico 4/11, Razón y vida (pp. 331-348).

San Martín, J. (2015). La nueva imagen de Husserl. Lecciones de Guanajuato. Madrid: Trotta. 